Asian Social Work Journal (ASWJ), Volume 5, Issue 1, (page 1 - 11), 2020

DOI: https://doi.org/10.47405/aswj.v5i1.113

\begin{tabular}{|c|}
\hline $\begin{array}{c}\text { Asian SOCIAL WORK } \\
\text { JURRAL } \\
\text { (ASW) }\end{array}$ \\
Volume 5, Issue 1, March 2020 \\
e-ISSN : 0128-1577 \\
Journal home page: \\
www.msocialwork.com \\
\hline
\end{tabular}

\title{
Flourishing of Female-Student Flood Survivors: An Overview of Women's Positive Growth
}

\author{
Etti Isnaini ${ }^{1}$, Siti Urbayatun ${ }^{1}$ \\ 1Faculty of Psychology, Universitas Ahmad Dahlan, Indonesia \\ Correspondence: Etti Isnaini (ettiisnaini.april@gmail.com)
}

\begin{abstract}
This study aimed to examine the dynamics and factors that influence flourishing in female flood survivors. flourishing is defined as a condition in which life a person experiences happiness and meaningfulness. The research used a qualitative method by in-depth interviews. The subjects were seven female flood survivors who had moderate to high levels of flourishing. The data were analyzed using the thematic analysis by coding the obtained descriptive data. The credibility of the data was confirmed by a significant other as a reliable source that has a thorough understanding of the subject's life. The results showed that survivors perceived that they flourished because they had a strong motivation to achieve their desired goals. A positive relationship with friends, family, and lecturers lead survivors to perceive that there are no obstacles to attain their goals. Student survivors also play their role as students, family members, and community members seriously (engagement), due to a sense of responsibility towards their own quality of life and success which they perceive is selfdetermined. A fighting spirit (motivation), a sense of care or concern, gratitude, and a resilient and robust personality are important factors that influence subjects flourishing.
\end{abstract}

Key words: engagement, flourishing, positive relationship, purpose, survivor

\section{Introduction}

Disaster survivors experience more negative psychological impact, then need social support for resilience in order to be able to restore their quality of life. The negative psychological impact can be caused by property loss, loss of family members, or changes in their mundane life. Data shows that the Imogiri flood effected 23 areas in nine sub-districts, which were submerged in 1 to 1.5 meters of water, leading to the death of five (KRJogya.com, 18 March 2019). Survivors experienced fear and anxiety about property loss and death. Interviews conducted on April 13, 14 and 20, 2019, found that the survivors experienced fear, stress, and anxiety when the flood hit their home a second time. This description of the student survivors' psychological condition implies that it may worsen their quality of life, if there is no positive coping when facing a disaster.

Disaster survivors need a process to rise back or revert back to the way life was prior to the disaster. There have been various studies in positive psychology that examine the relationship between wellbeing, happiness, and flourishing. The development of this concept has lead to a lot of research linking flourishing with the quality of one's life. Research by Raop \& Kadir (2011) examined the relationship between meaningfulness of life and gratitude which correlates significantly with subjective happiness. The ability of female students to find happiness in interpreting an event is in line with the description of flourishing stated in positive psychology research. flourishing is closely related to happiness and 


\section{DOI: https://doi.org/10.47405/aswj.v5i1.113}

subjective well-being. Individuals who have a high level of flourishing are described to experience positive emotions. Diener (2010) refutes this idea through his research, which found that flourishing depicts effect, meaning that it involves not only positive but also negative emotions. Disaster survivors experience more negative effect but may still attempt to flourish. Female college students' attempt to continue living their lives and playing their roles is part of a process that leads to a more meaningful, happier life and eventually to the stage of flourishing.

Feelings of gratitude, despite the death of a loved one, give rise to feelings of gratitude and the assumption that God is still providing an opportunity to live. There are also survivors who attempt to help other people affected by flood despite being afraid to go through heavy flood currents. Meaningfulness and gratification lead to the emergence of subjective happiness and the flourishing of a female student. A number of research related to students and disasters indicate that there are factors and specific techniques that can help reduce the psychological impact experienced by survivors (Ladd, Gill, \& Marszalek, 2007; Kapucu \& Khosa, 2013; Goyena, 2019). After a disaster experience, a person needs to learn to develop their strengths, continue to survive, and be productive in living life after being affected by flooding. Students are individuals who have academic assignments that are bounded by rules and are demanded to be productive despite being affected by floods.

This research differs from previous studies, which examines the negative impact of a disaster. Instead, this study looks at how flourishing occurs following a disaster, particularly in female students. Past studies have proven that the psychological impact that arises after a flood disaster is different for female and male students. female survivors tend to build resilience sooner after the disaster occurs. Based on research conducted by Oktarina and Afiatin (2013), female survivors of the Merapi eruption were able to overcome psychological problems that arise as a result of disasters using religious coping. Female survivors are resilient due to the existence of more positive thoughts regarding the occurred disasters, giving rise to hope and a strong belief in the face of misfortune. Negative emotions such as fear and sadness after the experienced tragedy can be reduced by way of dzikir, which leads to a more positive outlook on the event.

After a disaster, female survivors can carry out active strategies more openly and strive to carry out their daily activities. Student survivors have little to do with activities that require physical energy and tend to take part in activities that are more strategic in nature. Qualitative research conducted by Wijayanti, Pneumatica, and Nurjannah (2018) aimed to explore the adaptation strategies of females in rebuilding their socio-economic life after the occurrence of a flash flood in Bima. The results of their study show that survivors can sustain their lives with a strategy that is quite effective. Female survivors were able to rebuild their socioeconomic life and try to be more adaptive to climate change, allowing them to be better prepared in planning agricultural land management (Wijayanti, Pneumatica, \& Nurjannah, 2018). Even so, their lack of knowledge and skills in the creative economy is an obstacle for many survivors who strive to improve financially. However, they are able to socially establish working relationships to support the reconstruction of their lives.

The above description of female survivors' ability shows that flourishing after the experience of a flood disaster can be judged based on active efforts to improve life, for example, by continuing to land cultivation, as well as improving relationship strategies to obtain financial assistance to support their family's economic planning. A life that continues to grow and develop implies an individual's ability to actively and happily carry out activities in his or her life, both socially and economically (Blickhan, 2018). Female flood survivors not only lament their fate and passively wait at home but take part in activities that can foster motivation to live through self-empowerment.

Individuals who can ensure their well-being can be said to have reached a concept of happiness called flourishing. Both the term flourishing and happiness are used to describe the quality of a person's life in a specific time period or to evaluate one's life as a whole or a certain period (Villieux, Sovet, Jung, \& Guilbert, 2016). Based on the description above, this study aimed to explore the dynamics of flourishing in female students affected by flood as well as the factors that influence their flourishing. 
DOI: https://doi.org/10.47405/aswj.v5i1.113

\section{Data Collection Method}

This research used a qualitative phenomenological approach. Creswell (2015) stated that phenomenology is able to describe the structure of consciousness in a human's experience of expressing their subjective reality. The experience description of flourishing female flood survivors was explored using in-depth interviews. Before conducting the interviews, the researcher informs the research objectives to the participants in a written consent form, which also asks for voluntary participation and a description of the rights and obligations of researchers and participants during the data collection. The ethical conduct of building trust between researchers and participants is essential to understand because, in qualitative research, an open relationship is very beneficial for researchers to acquire data that is in accordance with the expected goals.

According to Creswell (2015), during the planning process of a qualitative study, researchers need to consider the possibility of facing several ethical problems; hence, researchers should plan from the beginning on how to overcome them. An important thing to keep in mind is the need to build a supportive relationship and mutual respect for the parties involved, including with the participants. Determination of research participants is based on consideration of sample criteria, that is, students who were affected by the flood disaster in 2019 , as well as those who achieved a moderate of high result in the flourishing scale screening. In addition, participants were willing to volunteer to become a source of data and interviews are conducted with significant others for the data triangulation process. After the collection of research data in the form of sound recording, the results of the interview were transcribed into a verbatim.

Researchers then conducted a thematic analysis on the interview verbatim. First, the researcher read the transcript repeatedly to get an understanding of the case or problem. Second, the researcher wrote down the meaning of the "descriptive" while reading the interview transcript. In in a separate colomn besides the verbatim transcript, researchers noted compacted facts, themes that emerge as well as keywords that can capture the essence of the data from the text being read. Keywords are a form of coding, which can also be a temporary conclusion, something that suddenly arises in the mind, or a temporary interpretation of the researcher. At this stage, the conceptual inference was not yet made. In a separate sheet, the researcher listed the emerging themes and explored the relationships between them, thus presenting a pattern of relations between categories, which also serves as a conclusion instead of a single theme.

\section{Results And Discussion}

\section{Description of Participants}

Based on the results of the screening using the flourishing scale, eight out of ten female students at the flood site had a medium or high flourishing category. Of the eight survivors, seven of them were willing to be interviewed. One participant resigned because she did not have time for the interview. The following is an illustration of the seven participants who were sampled in this study.

The following is an individual description of each participant:

Participant A is the second-born of three siblings. At the time of data collection, participant A was pursuing her bachelor's education in the PGSD (Primary Teacher Education) Department of a state university in Yogyakarta. Participant A received the from the Bidikmisi student achievement scholarship at school. Her family initially did not give permission for her to attend university due to their financial condition (her family was considered to have middle-low socioeconomic status). Her father worked as an occasional construction worker, and her mother has passed away. Participant A's sister was still in high school, so her family struggled to pay for university fees. These conditions lead participant A to find additional income by tutoring private lessons. 
DOI: https://doi.org/10.47405/aswj.v5i1.113

Table 1: Description of Participants

\begin{tabular}{|c|c|c|c|c|c|}
\hline Participant & Sex & Marriage Status & Age & Education & $\begin{array}{l}\text { flourishing } \\
\text { Category }\end{array}$ \\
\hline $\mathrm{A}$ & Female & Not yet married & 22 & $\begin{array}{l}\text { S1 PGSD (Bachelor of } \\
\text { Primary Teacher } \\
\text { Education) }\end{array}$ & Medium \\
\hline B & Female & Not yet married & 21 & $\begin{array}{l}\text { S1 Agribisnis (Bachelor of } \\
\text { Agribusiness) }\end{array}$ & Medium \\
\hline $\mathrm{C}$ & Female & Not yet married & 20 & $\begin{array}{l}\text { D3 Analis Kesehatan } \\
\text { (Vocational Diploma as } \\
\text { Health Analyst) }\end{array}$ & Medium \\
\hline D & Female & Not yet married & 23 & $\begin{array}{l}\text { S1 PKN (Bachelor of } \\
\text { Civic Education) }\end{array}$ & High \\
\hline E & Female & Married & 24 & $\begin{array}{l}\text { S1 PAI (Bachelor or } \\
\text { Islamic Religious } \\
\text { Education) }\end{array}$ & Medium \\
\hline $\mathrm{F}$ & Female & Not yet married & 21 & $\begin{array}{l}\text { D3 Admin. Perkantoran } \\
\text { (Vocational Diploma of } \\
\text { Office Affairs) }\end{array}$ & High \\
\hline G & Female & Not yet married & 22 & $\begin{array}{l}\text { S1 Psikologi (Bachelor of } \\
\text { Psychology) }\end{array}$ & Medium \\
\hline
\end{tabular}

Participant B is also the second-born of two siblings. At the time of data collection, participant B was pursuing attending her bachelor's education at the Department of Agribusiness at a private university in Yogyakarta. Participant B initially did not get permission from her extended family to continue her education to the university level. Upon graduating from high school, participant B began working at a shop and continued to do during the time of data collection. Participant B's parents open a food stall that sells retail gasoline at home. Her family's poor economic conditions encouraged participant B to work while attending university.

Participant $\mathrm{C}$ is the second-born of three siblings. Participant $\mathrm{C}$ 's sister is currently in the army $-\mathrm{a}$ job she started after the flood disaster. At the time of data collection, participant $\mathrm{C}$ was pursuing a student pursuing a vocational degree in health analysis. Her father is a veterinarian, and her mother is a housewife. Until the third semester, her journey as a university student has been relatively smooth. During the planning stage for university, she did not face obstacles of disapproval from parents and family.

Participant D is the second-born of four siblings. Participant D's sister died when she was 13 years old. In the beginning, participant $\mathrm{D}$ did not get permission from her extended family to attend university, but her mother tried to support her decision despite feeling pessimistic about the learning process. Participant D's father works as construction labor in Jakarta while her mother is a tailor. Since high school, participant $\mathrm{D}$ has actively participated in many organizational activities. Participant $\mathrm{D}$ has held a number of positions in school organizations she participated in. Participant D recently began working as an honorary teacher at a school near her home.

Participant E is the second-born of three siblings. Participant $\mathrm{E}$ is married and lives with her parents. Participant $\mathrm{E}$ is in her $10^{\text {th }}$ semester of university. In addition to lectures, participant $\mathrm{E}$ is also an honorary teacher at a madrasa. Participant E married about a year ago but has yet to have children and is eager to complete his studies.

Participant F is the second-born of three siblings. Participant F's parents work as a pedicab driver and housewife. Participant $\mathrm{F}$ had the support of her older sister to pursue the vocational degree she desired despite her parents being pessimistic about it at the beginning. The Bidikmisi scholarship she acquired motivated participant $\mathrm{F}$ to complete her college education. Participant $\mathrm{F}$ also worked part-time as a private tutor in between college responsibilities. 
DOI: https://doi.org/10.47405/aswj.v5i1.113

Participant $\mathrm{G}$ is the first-born of two siblings. During high school, participant $\mathrm{G}$ already had a strong desire to continue her education to the university level. Participant $G$ also acquired a Bidikmisi scholarship, which allowed her to major in what she wants. When she initially decided to attend university, participant $\mathrm{G}$ did not get permission and support from her parents and family members. A strong eagerness leads participant $G$ to attend college while working as a private tutor.

\section{The Flourishing Level}

Imogiri flood survivors flourished through the process of learning and eagerness to excel. This strong motivation leads female student flood survivors to have fewer moments of worry about the problems they face, both in their academic and daily lives. Positive feelings such as "relieved, comfortable, and plong (carefree)" led to the willingness and seriousness of survivors to be involved in activities outside of their academic responsibilities. In relation to the flood disaster, a young woman in the community does not have much role in the post-disaster recovery process. Survivor students are more involved in household responsibilities and personal activities. This condition did not affect the motivation of survivors to complete academic assignments and engage in social activities in their respective communities following the disaster. Students feel grateful for their achievements in college and strive to be responsible by graduating from college according to the targeted time limit given by the scholarship provider. The support of close friends, both from within campus or the surrounding environment, becomes a student's modality to overcome life problems, leading to constant feeling of happiness and flourishing through the stages of life. Based on these dynamics, it can be concluded that female students who are survivors of the Imogiri flood flourished due to social support, achievement motivation, and self-responsibility.

The flourishing of the seven female student flood survivors can be categorized into two categories: high and medium. The dynamics of high flourishing individuals is explained in the following diagram.

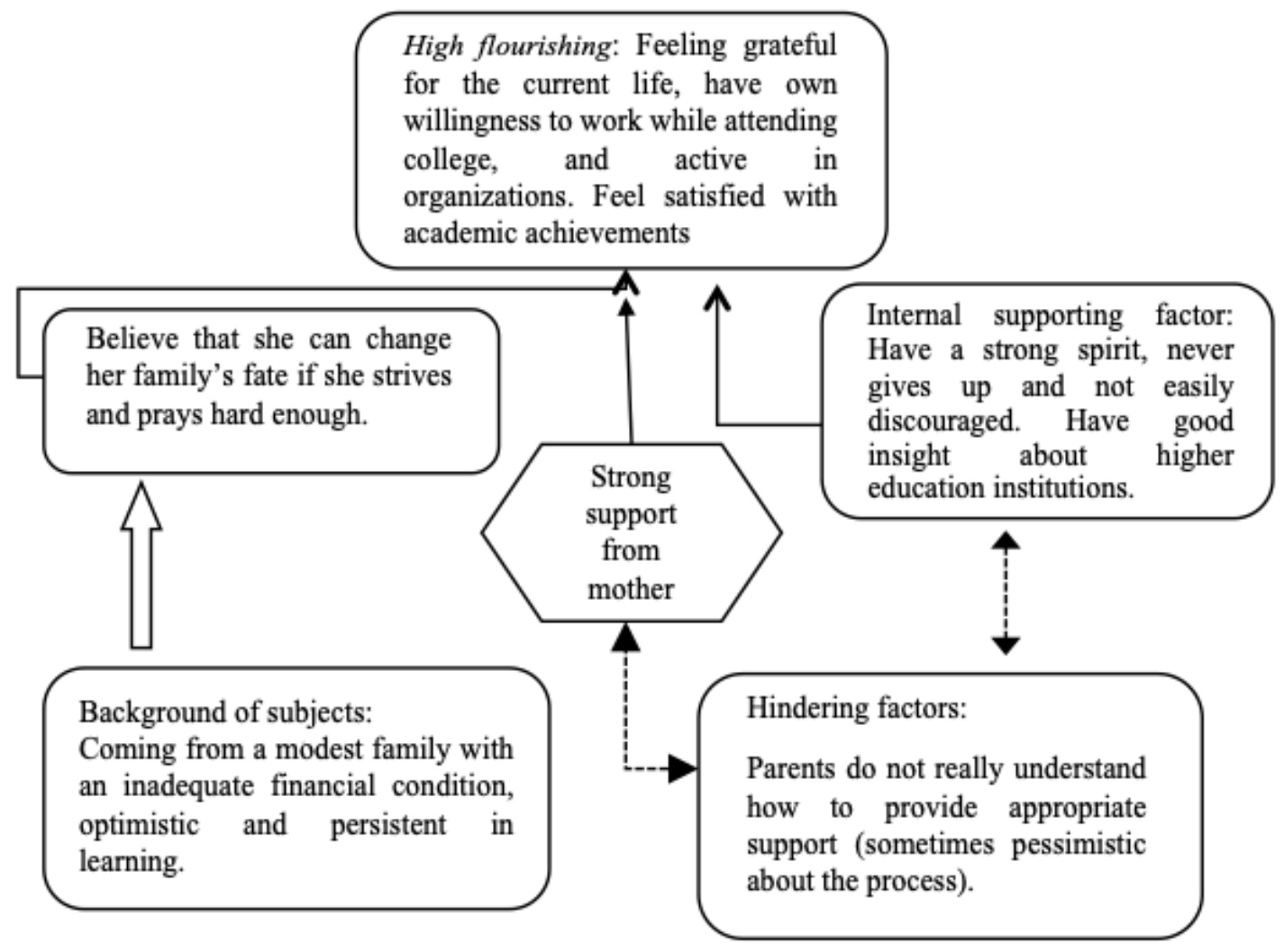

Figure 1. Dynamics of high flourishing participants 
DOI: https://doi.org/10.47405/aswj.v5i1.113

Explanation:

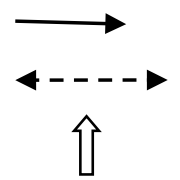

$$
\begin{aligned}
& \text { : has a positive influence on flourishing } \\
& \text { : negative interaction } \\
& \text { : strategy when facing a problem }
\end{aligned}
$$

Their challenging life leads female student flood survivors to develop strength and resilience, allowing them not to be discouraged in continuing their activities, primarily carrying out the responsibility of attending lectures. Factors that are very influential in allowing female student survivors to remain optimal as well as satisfied with themselves and their lives, include feeling grateful to Allah SWT for the opportunity to continue studying, feeling happy for the support of family and friend and being together during the disaster, and have a strong motivation and enthusiasm to successfully complete college.

Furthermore, two female student survivors who had high-flourishing carried out their academic responsibilities while working. The two of them interpret their life's journey positively. The female student survivors perceive that they feel more grateful for their current life, after initially going through disagreements and receiving scorns from extended family members who disagree with her intention to continue her studies to higher education. The two survivors were able to withstand "tests" like floods without experiencing negative psychological impact for too long. Their spirit and sense of responsibility enable them to complete their assignments while also playing their community roles after the flood. The desire to change the family's economic fate became the reason female student survivors try to win scholarships and graduate on time. Following these achievements, the student felt very grateful and satisfied with the life struggle she went through.

Aside from what has been stated above, the other five female student survivors have medium levels of flourishing. The following diagram is an illustration of the dynamics:

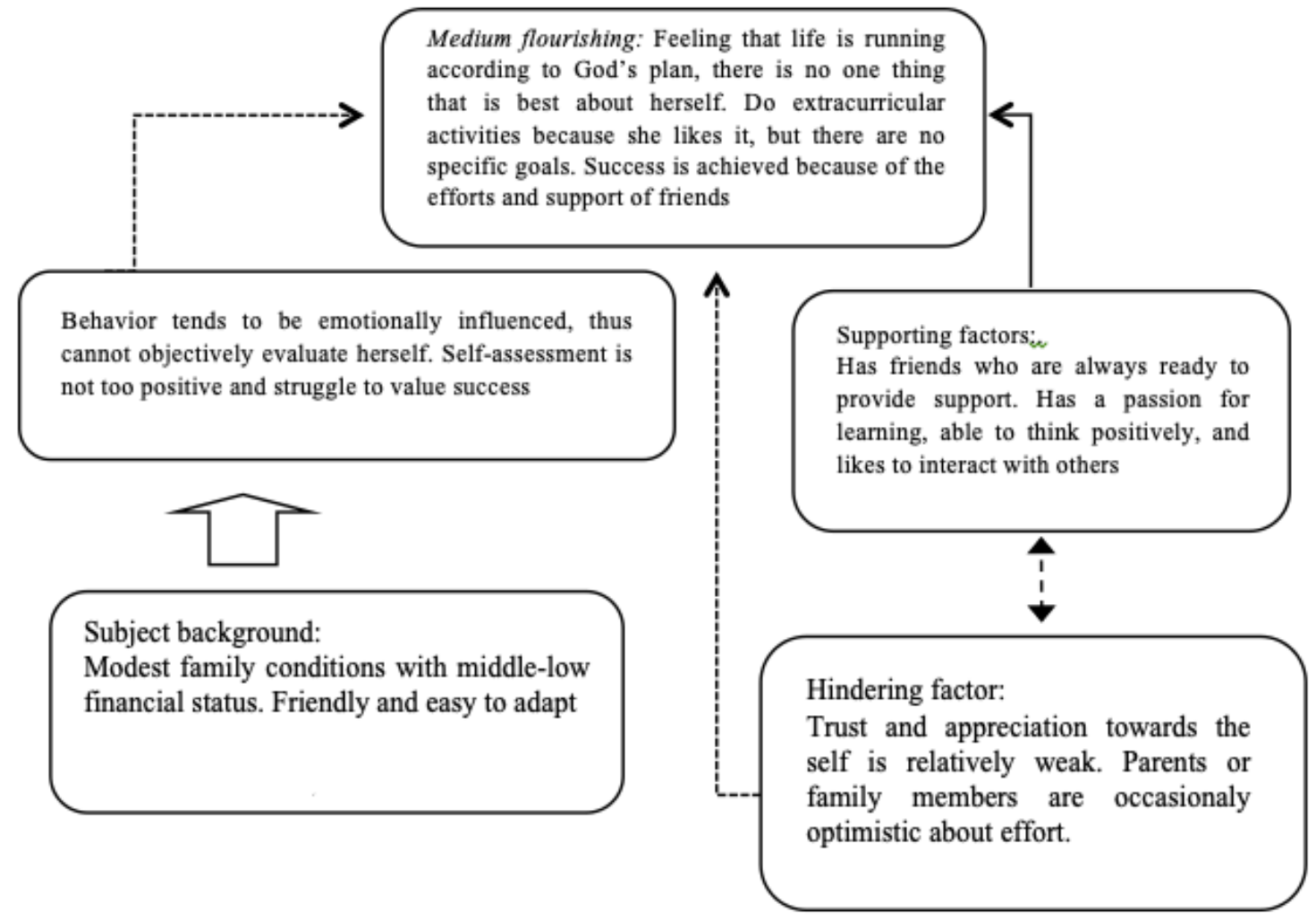

Figure 2. Dynamics of medium flourishing participants 
DOI: https://doi.org/10.47405/aswj.v5i1.113

Explanation:

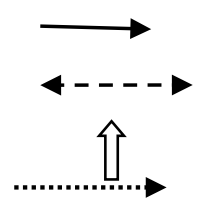

$$
\begin{aligned}
& \text { : influence the increase of flourishing } \\
& \text { : negative interaction } \\
& : \text { strategy when facing a problem } \\
& : \text { influence in the decrease of flourishing }
\end{aligned}
$$

Participants A, B, and G experienced adverse psychological effects when the flood occurred. Judging from their perceived loss, all three participants experienced the same conditions during the flood. All three participants felt adverse psychological effects such as feelings of anxiety and worry. However, the impact did not really interfere with their activities after the disaster. Participant A was able to overcome this, because three days after the flood, she thought that the atmosphere was like usual again so that there was nothing to fear. The following delivered by participant A:

"When did it start? Oh no, I don't know, as time passes by, I guess. Now that's because well there a feeling of relief, like before (the disaster), you can't really feel the flood, I mean the traces are already like it used to be, so (I feel) carefree. That's only for one night, it's okay, so it doesn't drag on for me."

"What's it called, like accepting, accepting the surrounding reality, not sure how to say it hehe. What's important is to calm down, that was my attitude - to calm down, oh this means it's over, that's it, and it's done done done. It will be better tomorrow. Hopefully, it does not flood again. That's how I do it; it's more in the mindset."

The ability to think positively in seeing an incident was also experienced by participants B and G. Both students also overcame the negative psychological impact of the flood disaster by learning from the 2017 flood incident. Students understood that flooding was only temporary, so within a few days, they were active again like the ordinary and not being too impacted. The condition of oneself and one's family, which was felt by the three female students, greater affected their psychological state, both positively and negatively. The family of participants $\mathrm{C}$ and $\mathrm{E}$ had better financial conditions than the previous three participants and did not feel a substantial impact during the disaster due to the safer position of their house.

These five female students felt that their lives were running as they should be, not really being affected by the flood. Practical ways of thinking help them feel not so impacted by the disaster subsequently not affecting activities. The family of participants $\mathrm{C}$ and $\mathrm{E}$ are better off financially compared to participants A, B, and G. However, these conditions are not so relevant with flourishing. These five female students felt that their lives were running in accordance with the terms that had been arranged by God.

\section{Influencing Factors}

Participants who have high levels of flourishing come from families with modest economic conditions. Out of five participants with moderate flourishing level, three were also from modest families with parents whose income ranges between Rp. 800,000 to Rp. 1,000,000. Such parents' income lead survivors try to strive to achieve their goal in becoming a university graduate. Participants $\mathrm{B}, \mathrm{C}$, and $\mathrm{E}$ also come from modest families, although both participants have their tuition paid by their parents and worked while attending college. Aside from attending college, six participants tried to make ends meet by working part-time. This work factor also affects survivors in growing into individuals who are tough and grateful. The seven participants were college students with an age range of 20-24 years, meaning that they are in their early adulthood. Economic factors, occupation, and age are included in sociodemographic factors that influence the flourishing of Imogiri flood survivors.

Five out of the seven research participants were individuals who have strong and motivated personalities and have a high enthusiasm for learning. Participants A, B, D, F, and G were born from a modest family and strived to show their respective families that a high enthusiasm for learning can lead 
one to become a university graduate. The seven participants are extroverts who like to interact with other people. All participants are involved in community activities, which allowed them to learn how to live life. The seven participants are Muslims who lived in an environment with quite frequent otherwise bisa strong religious atmosphere. Participants A, D, F, G feel that by social interaction lead them to become more grateful and realize that Allah SWT has given them many blessings, in the form of the ability for advanced thinking and ease of learning. The four participants also became closer to the God, after attending university thus far. Participants D and F have graduated and almost graduated respectively, while participants A, E, and G feel grateful to have been able to complete their seminar proposal, and strive to graduate in the near future.

Female student survivors who experienced more severe impacts had relatively high flourishing. As a result of the flood, participants $\mathrm{D}$ and $\mathrm{F}$ felt a significant negative psychological impact, in addition to losing some valuable items that support their academic learning process, namely laptops and practicum report files. Gratefulness and meaningfulness in life became more apparent, and higher experience of flourishing than the other five participants.

\section{Dynamic of Flourishing women}

Survivors who experienced negative psychological impacts, such as feelings of trauma, anxiety, worry, and panic, experience more flourishing. The process of losing valuable possessions leads survivors to receive more material support and psychological support from those closest to them. The condition experienced by survivors is in line with the theory of positive psychological theory which states that flourishing can be achieved not only when one feels free from pressure or problems, but when one is also able to accept themselves and their past, develop or nurture their self, believe that life is meaningful and has a purpose, has a positive quality relationship with others, has the ability to manage life and surroundings effectively, and is able to determine their own actions (Ryff \& Singer, 2014). By changing thoughts and feelings, a person is expected to be able to shift his or her behavior from negative to positive. With a change in mindset and more positive behavior, the flourishing of an individual can also increase as it is free from feelings of distress (Carr, 2011).

In positive psychology, the term flourishing is a condition where a person is able to develop his or herself to the fullest. Self-development in the concept of flourishing implies that an individual is able to function optimally in accordance with his or her potential. The goal of flourishing is to achieve overall physical and mental functioning (Seligman, 2011). Seligman stated that the purpose of positive psychology is "Authentic Happiness," which includes 3 dimensions (positive emotion, engagement, and meaning). In 2006, the concept was refined into 5 dimensions (positive emotion, engagement, positive relationship, meaning, and accomplishment) commonly abbreviated as PERMA and subsequently known as flourishing.

Positive psychology research offers a different theory regarding the process of restoring one's psychological condition, which not only focuses on oneself but how a person can also benefit the environment, this process is referred to as flourishing. In his research, Effendy (2016) states that flourishing is a synonym of a high level of mental well-being and symbolizes mental health (Huppert, 2011; Keyes, 2010; Ryff \& Singer, 2014). Diener added that in the concept of flourishing, life purpose, positive relationship, engagement, competence, self-esteem, optimism are factors that enrich wellbeing. Thus, people with high levels of positive emotions at have good psychological, social functions, mentally healthy as a flourishing. This explanation shows that flourishing is a high level of well-being (Effendy, 2016).

Female student survivors students are considered vulnerable due to their gender, as they are rarely involved in and have few roles after the disaster hits. Research findings show that female survivors do not contribute much to the post-disaster recovery process but are more involved in household responsibilities, personal activities, and academic activities on campus. The study of gender and disaster has focused almost exclusively on the vulnerabilities and certain capacities of women. Through the vulnerability paradigm, many disaster studies are interested in gender inequality, as it has become clear that disasters affect to position women disproportionately. Many studies have emphasized that, in 
Asian Social Work Journal (ASWJ), Volume 5, Issue 1, (page 1 - 11), 2020

DOI: https://doi.org/10.47405/aswj.v5i1.113

many places and communities, women lose access to means of protection from natural hazards, which are instead more are available to men due to unequal power relations at the local and international levels (Gaillard et al., 2017).

Other research found that female survivors have a high level of flourishing, with certain coping pattern tendencies, such as seeking social support when facing problems, specifically the help of family and friends. According to the research of Schotanus-Dijkstra et al. (2016), social support from spouse, family, and neighbors has a positive correlation with flourishing. Additionally, Fink (2014) stated that a supportive university climate contributes to the increase of student flourishing. Various other social supports, such as support from the government, mental health experts, and religious communities, are also associated with the increase of a person's level of flourishing. (Du Plooy et al., 2018). The support of close friends, both on campus or in the surrounding environment, becomes a student's modality in overcoming life problems, ensuring constant feelings of happiness and flourishing every stage of life. Social support, experiences of positive and negative events, and physical health are among the situational factors that effect flourishing.

In addition, motivation for achievement and a sense of responsibility towards oneself are also essential factors for surviving students to grow and develop into flourishing women. The modest economic condition of the family is the biggest motivation for female survivors to excel and achieve in higher education. Keswari (2019) states that flourishing is also influenced by age, sex, economic status, social support, religiosity and personality. Research conducted by Wiedemann, C.S (2019) shows that the existence of clear goals can increase one's motivation to act, so as to feel useful and meaningful when successful with it, subsequently leading the individual to flourish. In addition, research on undergraduate students in the Philippines shows that there is a relationship between motivation for academic achievement and flourishing (Datu, J.A.D., Labarda, C.E., Salanga, M.G.C., 2019).

Spiritual factors such as gratitude and increase of worship activities in female student survivors also influence flourishing. Other research conducted by Howell and Buro (2014) in Canadian students measured predictors of subjective well-being predictors, using the flourishing scale and the scale of positive-negative experiences. Self-transcendence and value conservation is the highest predictors of the flourishing scale. Self-transcendence is related to the development of the student's self-concept in an effort to reflect and introspect upon his or her inner (batiniah), outer (lahiriah), and worldly (duniawi). In addition, Diener (2010) found that happiness is also determined by external factors, which are related to individual demographics, such as religion. Based on this explanation, female survivors who have strong religious beliefs and are also actively engaged in religious activities, feel more grateful and perceive a meaningful life.

\section{Conclusion}

The dynamics and factors that influence the flourishing of female survivors can be illustrated by the coping pattern of females who tend to seek social support in the face of problems, namely the support of family and friends. The age range of participants did not significantly affect the development of flourishing individuals. A female survivor does not have much role in the post-disaster recovery process in the social environment but is more involved in household responsibilities, personal activities, and academic activities on campus. The support of close friends, both from within campus or in the surrounding environment, becomes a student's modality to overcome life problems, allowing a constant feeling of happiness, flourishing through the stages of his life.

Based on these dynamics, it can be concluded that female students who are survivors of the Imogiri flood flourished due to social support, achievement motivation, and self-responsibility. Factors that influence flourishing are feelings of gratitude for the blessing of Allah SWT in the form of permission to continue studying, feelings of happiness due to support from family and friends and sense of togetherness during the flood, and a strong motivation and enthusiasm to successfully finish college. Furthermore, the seven female student survivors have a high engagement with their school responsibilities and interpret their life's journey so far positively. The seven female students consider 
DOI: https://doi.org/10.47405/aswj.v5i1.113

that they feel more grateful for life at this time (after the flood), compared to a long time ago through disagreements and scorns from extended families regarding their intention to continue their studies to higher education.

Participants did not experience prolonged negative psychological impact due to having positive coping strategies in responding to the disaster. A strong fighting spirit and sense of responsibility have elicited efforts to completing assignments and play their roles in the community after the flood. The desire to change the fate and condition of their family's economy became the reason survivors try to acquire scholarships and graduate on time. In addition, the beliefs or spirituality of female survivors and the increase in worship activities gave rise to a positive perspective in responding to the disaster. The similarity of religion, culture, and economic conditions of the family more or less influence the dynamics of flourishing of female flood survivors.

\section{Acknowledgment}

The research is supported by the Directorate for Research and Community Service under the Directorate General of Strengthening for Research and Development of the Ministry of Research, Technology and Higher Education (Research Contract Number: PTM-014 /SKPP.TT/LPPM $\mathrm{UAD} / \mathrm{III} / 2019)$.

\section{References}

Blickhan, D. (2018). Positive Psychologie: Ein Handbuch für die Praxis. Junfermann Verlag GmbH.

Carr, A. (2011). Positive psychology. In A. Carr (Ed.), Positive psychology : The science of happiness and human streght second edition (pp. 329-339). London and New York: Routledge.

Creswell, John, W. (2015). Penelitian Kualitatif \& Desian Riset. Yogyakarta. Pustaka Pelajar

Datu, J. A. D., Labarda, C. E., \& Salanga, M. G. C. (2019). Flourishing is Associated with Achievement Goal Orientations and Academic Delay of Gratification in a Collectivist Context. Journal of Happiness Studies, 1-12.

Diener, E., Wirtz, A. D., Tov, A. W., Shigehiro, D. C. A., \& Robert, O. A. (2010). New Well-being Measures: Short Scales to Assess Flourishing and Positive and Negative Feelings. 143-156. https://doi.org/10.1007/s1 1205-009-9493-y

Du Plooy, D. R., Lyons, A., \& Kashima, E. S. (2018). Predictors of flourishing and psychological distress among migrants to Australia: a dual continuum approach. Journal of Happiness Studies, 20(2), 561-578.

Dijkstra, M.S., dkk. (2016). What Factors are Associated with Flourishing? Results from a Large Representative National Sample. Journal of Happiness Study. 17: 1351-1370.

Effendy, N. (2016). Konsep Flourishing dalam Psikologi Positif: Subjective Well-being atau berbeda. Psychology \& Humanity, 327-333.

Fink, J. E. (2014). Flourishing: Exploring predictors of mental health within the college environment. Journal of American College Health, 62(6), 380-388.

Gaillard, J. C., Sanz, K., Balgos, B. C., Dalisay, S. N. M., Gorman-Murray, A., Smith, F., \& Toelupe, V. A. (2017). Beyond men and women: a critical perspective on gender and disaster. Disasters, 41(3), 429-447.

Goyena, R. (2019). Journal of Chemical Information and Modeling, 53(9), 1689-1699. https://doi.org/10.1017/CBO9781107415324.004.

Howell, A. J., \& Buro, K. (2014). Measuring and Predicting Student Well-Being : Further Evidence in Support of the Flourishing Scale and the Scale of Positive and Negative Experiences. https://doi.org/10.1007/s1 1205-014-0663-1.

Huppert, F. A. \& Timothy, T. C. So. (2011). Flourishing Across Europe: Aplication of a new conceptual framework for defining well-being. Springerlink, 110, 837-861.

KRJogya.com. (2019, 18 Maret). Sebaran Banjir Berdasar BPBD Bantul. Diakses pada 12 Oktober 2019, dari https://www.liputan6.com/regional/read/3919345/sebaran-banjir-berdasar-bpbdbantul. 
DOI: https://doi.org/10.47405/aswj.v5i1.113

Kapucu, N., \& Khosa, S. (2013). Disaster Resiliency and Culture of Preparedness for University and College Campuses. In Administration and Society (Vol. 45). https://doi.org/10.1177/0095399712471626.

Keswari, Dyah, R, A. (2019). Psikoterapi Positif Untuk Peningkatan Flourishing Penderita Gagal Ginjal (Tesis). Direktorat Program Pascasarjana Universitas Muhammadiyah Malang.

Keyes, C. L. (2010). Flourishing. The Corsini Encyclopedia of Psychology, 1-1.

Ladd, A. E., Gill, D. A., \& Marszalek, J. (2007). Riders from the Storm: Disaster Narratives of Relocated New Orleans College Students in the Aftermath of Hurricane Katrina. Journal of Public Management \& Social Policy, 51-80.

Octarina, M., \& Afiatin, T. (2013). Efektivitas pelatihan koping religius untuk meningkatkan resiliensi pada perempuan penyintas erupsi merapi. Jurnal Intervensi Psikologi, 5(1), 95-110.

Villieux, A., Sovet, L., Jung, S. C., \& Guilbert, L. (2016). Psychological flourishing: Validation of the French version of the Flourishing Scale and exploration of its relationships with personality traits. Personality and Individual Differences, 88, 1-5. https://doi.org/10.1016/j.paid.2015.08.027.

Raop, N. A., \& Kadir, N. B. Y. A. (2011). Pengertian Hidup, Syukur Dan Hubungannya Dengan Kegembiraan Subjektif Di Kalangan Pekerja. e-BANGI, 6(2), 10.

Ryff, C. D., \& Singer, B. (2014). Interpersonal flourishing : a positive health agenda for the new millennium. Personality and Social Psychology Review, 4(1), 30-44.

Schotanus-Dijkstra, M., Pieterse, M. E., Drossaert, C. H., Westerhof, G. J., De Graaf, R., Ten Have, M., \& Bohlmeijer, E. T. (2016). What factors are associated with flourishing? Results from a large representative national sample. Journal of happiness studies, 17(4), 1351-1370.

Seligman, M. E. P. (2011). Flourish: positive psychology and positive interventions. University of Michigan, 229-243.

Wiedemann, C. S. (2019). Purpose-Driven: Employee Engagement from a Human Flourishing Perspective.

Wijayanti, I., Pneumatica, O., \& Nurjannah, S. (2018). Pasca Bencana Banjir Bandang ( Studi Kasus Peran Perempuan. SIMULACRA, 1(iii), 5-18. 